\title{
Immunophenotypic characterisation and cytogenetic analysis of mesenchymal stem cells from equine bone marrow and foal umbilical cords during in vitro culture
}

\author{
Anatoliy Mazurkevych ${ }^{1}$, Mykola Malyuk ${ }^{1}$, Natalia Bezdieniezhnykh ${ }^{2}$, \\ Lyubov Starodub $^{3}$, Yuriy Kharkevych ${ }^{1}$, Evgen Brusko ${ }^{4}$, \\ Magdalena Gryzińska ${ }^{5}$, Andrzej Jakubczak \\ ${ }^{1}$ Department of Physiology, Pathophysiology and Immunology of Animals, \\ National University of Life and Environmental Sciences of Ukraine, 03041 Kyiv, Ukraine \\ ${ }^{2}$ Department of Experimental Cell Systems, \\ R.E. Kavetsky Institute of Experimental Pathology, Oncology and Radiobiology, \\ National Academy of Sciences of Ukraine, 03022 Kyiv, Ukraine \\ ${ }^{3}$ Laboratory of Genetics, Institute of Animal Breeding and Genetics, \\ National Academy of Agrarian Sciences of Ukraine, 08321 Kyiv, Ukraine \\ ${ }^{4}$ Equestrian Federation of Ukraine, 01054 Kyiv, Ukraine \\ ${ }^{5}$ Department of Biological Basis of Animal Production, Faculty of Biology and Animal Breeding, \\ University of Life Sciences in Lublin, 20-950 Lublin, Poland \\ magdalena.gryzinska@up.lublin.pl
}

Received: January 18, 2016 Accepted: July 21, 2016

\begin{abstract}
Introduction: The objective of the study was immunophenotypic and cytogenetic analysis of mesenchymal stem cells from equine bone marrow and foal umbilical cords during in vitro culture. Material and Methods: The mesenchymal stem cells were obtained from equine bone marrow of three horses and from foal umbilical cords of six foals. The cells were cultured in $\mathrm{CO}_{2}$ incubators by standard procedure. Quantitative abnormalities of chromosomes, i.e. aneuploidy and polyploidy, and structural aberrations, i.e. breaks in chromosomes and chromatid, were taken into account during the study. Results: The results of cytogenetic analysis of equine bone marrow mesenchymal stem cells at the third and fourth passages indicated that the level of karyotype variability of these cells corresponded to the spontaneous level of karyotype variability typical of the peripheral blood lymphocytes of this species. Equine bone marrow contained several clones of stem cells that differed in the expression of specific nuclear markers characteristic of proliferating cells. Conclusion: Mesenchymal stem cells from foal umbilical cords during in vitro cultivation are characterised by quantitative abnormalities of the chromosomal apparatus.
\end{abstract}

Keywords: horses, bone marrow, umbilical cord, mesenchymal cells, cytogenetic analysis.

\section{Introduction}

The pathology of the musculoskeletal system is a common problem in the sports horse industry due to the extremely high loads on the tendons, joints, etc. during training or sports competitions. Conservative methods for treating horses with injured tendons are often ineffective and are associated with a high risk of retraumatisation, in about $55 \%-66 \%$ of horses during subsequent physical activity (11).
Techniques using stem cells occupy a leading position among the scientific advances in regenerative therapy. Mesenchymal stem cells from animal bone marrow and adipose tissues are used most frequently. In recent years, however, an increased use of stem cells from non-embryonic mammalian organs, particularly from the umbilical cord, has been observed. The umbilical cord contains a new class of pluripotent stem cells with intermediate properties between those of embryonic and somatic stem cells $(8,21)$. These cells 
can be obtained without additional surgery or ethical constraints $(15,24)$. Subsequently, they can be successfully used in cell-regenerative therapy as autologous material for treatment of animals with musculoskeletal system pathology. However, an extremely important issue arising from the use of stem cells in cell-regenerative therapy is its safety, in terms of the risk of neoplastic transformation after administration in vivo. During in vitro culture mesenchymal stem cells undergo changes that result in cellular aging and reduced cell proliferation. Mutations which appear during cultivation may lead to neoplastic transformation of cells. For this reason, before being transplanted into animals, mesenchymal stem cells should be checked against the cancerous phenotype and tested for the presence of mutations that can lead to neoplastic transformation and tumour growth (7).

The literature offers conflicting data regarding the risk of spontaneous transformation of mesenchymal stem cells during in vitro culture $(2-4,16)$. Therefore, investigations of the biological properties of mesenchymal stem cells from equine bone marrow and foal umbilical cords as well as their cytogenetic analysis are highly relevant and timely tasks (13).

The objective of the study was to perform an immunophenotypic and cytogenetic analysis of mesenchymal stem cells from equine bone marrow and foal umbilical cords during in vitro culture.

\section{Material and Methods}

Obtaining mesenchymal stem cells from equine bone marrow. Bone marrow was collected from the iliac crest of clinically healthy one- to two-year-old horses. Three animals from the Derkulsk State Horse Stud (Novoderkul, Belovodsk district, Luhansk region) were used in the experiment. All manipulations were performed under general anaesthesia and subsequent infiltration of the soft tissues near the site of the bone puncture with $2 \%$ Lidocaine solution. The animals were sedated by intravenous injection with Detomidin (0.02 mg/kg b.w.) As a general anaesthetic, Propofol was administered intravenously at a dose of $2 \mathrm{mg} / \mathrm{kg}$ b.w.

Bone marrow was collected using a needle for the bone tissue trepanobiopsy (Sterylab, Italy). Before bone aspiration, the syringe was filled with heparin at 2-3 IU per $1 \mathrm{~mL}$ of its volume. After bone marrow aspiration, the syringe was disconnected from the needle, and the needle was removed by turning it anticlockwise. To stop bleeding, a sterile cotton-gauze swab was applied to the site of the skin puncture for a few minutes and then the puncture site was treated with a $5 \%$ alcoholic iodine solution.

To obtain the mononuclear cell fraction, the bone marrow aspirate was diluted with phosphate buffer solution at a ratio of 1:5 and centrifuged in a gradient density of Ficoll $(\rho=1.076)$ for $30 \mathrm{~min}$ at $300 \mathrm{~g}$.
Mononuclear cells in the amount of $625000 / \mathrm{cm}^{2}$ were transferred to Petri dishes $(\mathrm{d}=35 \mathrm{~mm})$ for culturing.

Obtaining mesenchymal cells from foal umbilical cords. Umbilical cords were obtained from foals of thoroughbred horses during birth (Millennium, Kliuchove village, Donetsk region, Volodarskii district).

Samples of the umbilical cords were obtained immediately after birth (six foals were used in the experiment). The cords were washed in tap water to fully remove foreign particles and transferred to a bowl with $70 \%$ ethanol for $5 \mathrm{~min}$. Then they were placed in a container filled with normal saline solution containing antibiotic and antimycotic agents, transferred to a transport container $\left(4^{\circ} \mathrm{C}\right)$, and transported to the laboratory. Further procedures were carried out in a sterile laminar hood. The umbilical cords were washed several times with PBS, released from the vessels, and cut into pieces of $3-5 \mathrm{~mm}$. Then the tissues were exposed to enzymatic disaggregation with $0.25 \%$ trypsin solution at $4^{\circ} \mathrm{C}$ for $36 \mathrm{~h}$. The cell suspension obtained was filtered through four layers of sterile gauze cloth, centrifuged, resuspended in culture media, and seeded in Petri dishes.

Cells cultivation. The cells from the equine bone marrow and umbilical cords were seeded in Petri dishes $(\mathrm{d}=35,60 \mathrm{~mm})$ and cultured in $\mathrm{CO}_{2}$ incubators $(5 \%$ $\mathrm{CO}_{2}$ and $37.0^{\circ} \mathrm{C}$ ) by standard procedure. The culture media contained 80\% Dulbecco's modified Eagle's medium and $20 \%$ foetal bovine serum with $10 \mu \mathrm{l} / \mathrm{mL}$ of antibiotic-antimycotic solution. The culture medium was replaced every $72 \mathrm{~h}$. When monolayer confluency reached about $80 \%-90 \%$, the cells were transferred to a suspension using $0.05 \%$ trypsin-EDTA solution and reseeded in a ratio of 1 to 3 . Microscopic analyses of cell culture quality were carried out using an Axiovert 40 inverted microscope (Carl Zeiss, Germany). The microscopic examination was conducted daily.

Immunophenotypic analysis. The cells were grown on cover glasses for 48-72 h. After the monolayer reached about $50 \%-70 \%$ confluency, the cells were fixed in fixing solution (methanol + acetone, $1: 1$ ) for $2 \mathrm{~h}$ at $20^{\circ} \mathrm{C}$, incubated with a $1 \%$ solution of bovine serum albumin (BSA), and treated with monoclonal antibodies: anti-PCNA (clone PC-10, NeoMarkers), Ki-67 (clone RB-9043-PO, Neomarkers), CD44 (clone 156-3C11, DiagnosticBioSystems), PanMuscleActin (clone 1a45C5, DiagnosticBioSystems), E-cadherin (clone SPM 471, ThermoScientific), $\mathrm{N}$-cadherin (clon CD 325, ThermoScientific), vimentin (V9, DiagnosticBioSystems), and CD24 (SN3b, NeoMarkers) for $30-60 \mathrm{~min}$ in accordance with the instructions for monoclonal antibody application. Then the PolyVue visualisation system (ThermoScientific) conjugated with peroxidase was used and enzyme activity was detected using diaminobenzidine (ThermoScientific) as a substrate. After conducting an immunocytochemical reaction, the preparations were washed with water and stained with Mayer 
haematoxylin (Sigma) for 15-30 s, and then placed in Faramount Aqueous Mounting Medium. The results were analysed by counting the number of positively stained cells (brown staining) and evaluated by the classical H-Score method: $\mathrm{S}=1 \mathrm{xA}+2 \mathrm{xB}+3 \mathrm{xC}$, where $\mathrm{S}-\mathrm{H}-\mathrm{Score}$ index. The values range from 0 (antigen not detected) to 300 (strong expression in $100 \%$ of cells); A - percentage of weakly stained cells; B - percentage of moderately stained cells; $\mathrm{C}$ - percentage of strongly stained cells.

Cytogenetic analysis. Cytogenetic analyses were performed on cultures of mesenchymal stem cells from equine bone marrow and umbilical cords of thoroughbred horses. Thirty metaphase plates obtained by a modified standard cytogenetic method were analysed in a cell culture of each passage investigated (18). Fixation of chromosomes was performed for $48 \mathrm{~h}$ after cell seeding. Colchicine was added to the culture medium at $0.05-0.5 \mu \mathrm{g} / \mathrm{mL}$ and the culture was incubated for $1.5-2 \mathrm{~h}$ at $37^{\circ} \mathrm{C}$. The cells were removed from the Petri dishes and a cell suspension was obtained by incubation for $1-5 \mathrm{~min}$ at $37^{\circ} \mathrm{C}$ in trypsinEDTA solution. The cells were maintained in metaphase by incubation for $30 \mathrm{~min}$ at $37^{\circ} \mathrm{C}$ in a warm hypotonic solution of $\mathrm{KCl}(0.56 \%)$ at a rate of $1 \mathrm{~mL}$ of cell suspension to $9 \mathrm{~mL}$ of hypotonic solution (1:9). Fixation of chromosomes was performed 3-4 times for 10-20 min in freshly prepared cooled fixative (methanol:glacial acetic acid, 3:1). The chromosome material obtained was stained for $40 \mathrm{~min}$ with $20 \%$ Giemsa stain solution (Merck, Germany). Metaphase plates were analysed using an Axiostar plus microscope (Carl Zeiss, Germany) at 100× and 1000×.

Quantitative abnormalities of chromosomes, i.e. aneuploidy and polyploidy, and structural aberrations, i.e. breaks in chromosomes and chromatid, were examined. A micronucleus test was performed on the material to estimate the number of binucleated cells (BC) and cells with micronuclei (CM), the mitotic index (MI), and the number of apoptotic cells (AC). The frequency of $\mathrm{BC}, \mathrm{CM}, \mathrm{MI}$, and $\mathrm{AC}$ was calculated in 1000 cells (\%o).

Statistical analysis. The results were statistically analysed using Student's $t$-test for significance of differences between means. Differences at $\mathrm{P} \leq 0.01$, $\mathrm{P} \leq 0.05$, and $\mathrm{P} \leq 0.001$ were considered significant or highly significant. The tables show the mean and standard deviation.

\section{Results}

Morphological features of cells of mesenchymal origin during in vitro culture. The main difficulty in obtaining mesenchymal stem cells (MSCs) from bone marrow is associated with the presence of several cell populations that are able to bind to the plastic culture dish. For this reason the primary cell cultures from the bone marrow were characterised by a considerable morphological heterogeneity until the $1^{\text {st }}$ and $2^{\text {nd }}$ passage. In this case, two types of cells predominated: round cells that grew in colonies and divided intensively over the first 9-13 d of in vitro cultivation (evidently endothelial precursors) and fibroblast-like cells. At the $2^{\text {nd }}$ passage the cell culture appeared completely homogeneous and contained actively proliferating fibroblast-like cells (Fig. 1. a1-a2).

The MSCs obtained from the umbilical cords and the primary MSCs from the bone marrow were characterised by a considerable morphological heterogeneity. However, during the cell adaptation at the $0^{\text {th }}$ and $1^{\text {st }}$ passages, the fibroblast-like cells of the umbilical cord (Fig. 1. b1-b2, c1-c2) were morphologically similar to the fibroblast-like cells from the bone marrow, and had a flattened shape and the same size in the longitudinal and transverse directions.

The Fig. 1. b1-b2 was obtained by photographing the cultures under a microscope during days 10-15 of the cultures. The primary culture of MSCs from the equine umbilical cord had a considerable morphological heterogeneity: along with fibroblastlike cells, round cells, which were clearly endothelial cells, were observed. However, at the $0^{\text {th }}$ passage, with the confluence of monolayer cells increasing to $70 \%-80 \%$, the round cells were replaced by fibroblast-like cells. At the $2^{\text {nd }}, 3^{\text {rd }}$, and consecutive passages of cultivation, the growth of round cells was not observed.

When $85 \%$ confluence was attained, in all cases, irrespective of the passage number, there was a significant decline in the mitotic activity of cellular elements of MSCs from the umbilical cord (Fig. 1. b1 b2, c1-c2).

After the $2^{\text {nd }}$ passage the cultures of MSCs from both sources were morphologically homogeneous and contained mostly small, active spindle cells (Fig. 1. a1, c2). After the $5^{\text {th }}$ passage, the culture of equine bone marrow stem cells and after the $7^{\text {th }}$ passage the culture of umbilical cord stem cells gradually lost their mitotic activity, and some cells became large and flattened.

At this stage, the growth of the cell population had almost stopped.

Phenotypic characterisation of equine bone marrow mesenchymal stem cells. Immunocytochemical analysis of the CD-receptor system of equine bone marrow stem cells at the early passages indicates that the set of specific proteins differs significantly in various clones of cultured cells and changes during cultivation. The data pertaining to the immunophenotypic profile of multipotent stem cells from equine bone marrow at the $2^{\text {nd }}$ and $5^{\text {th }}$ passages are given in Table 1 and Fig. 2. f-h. 

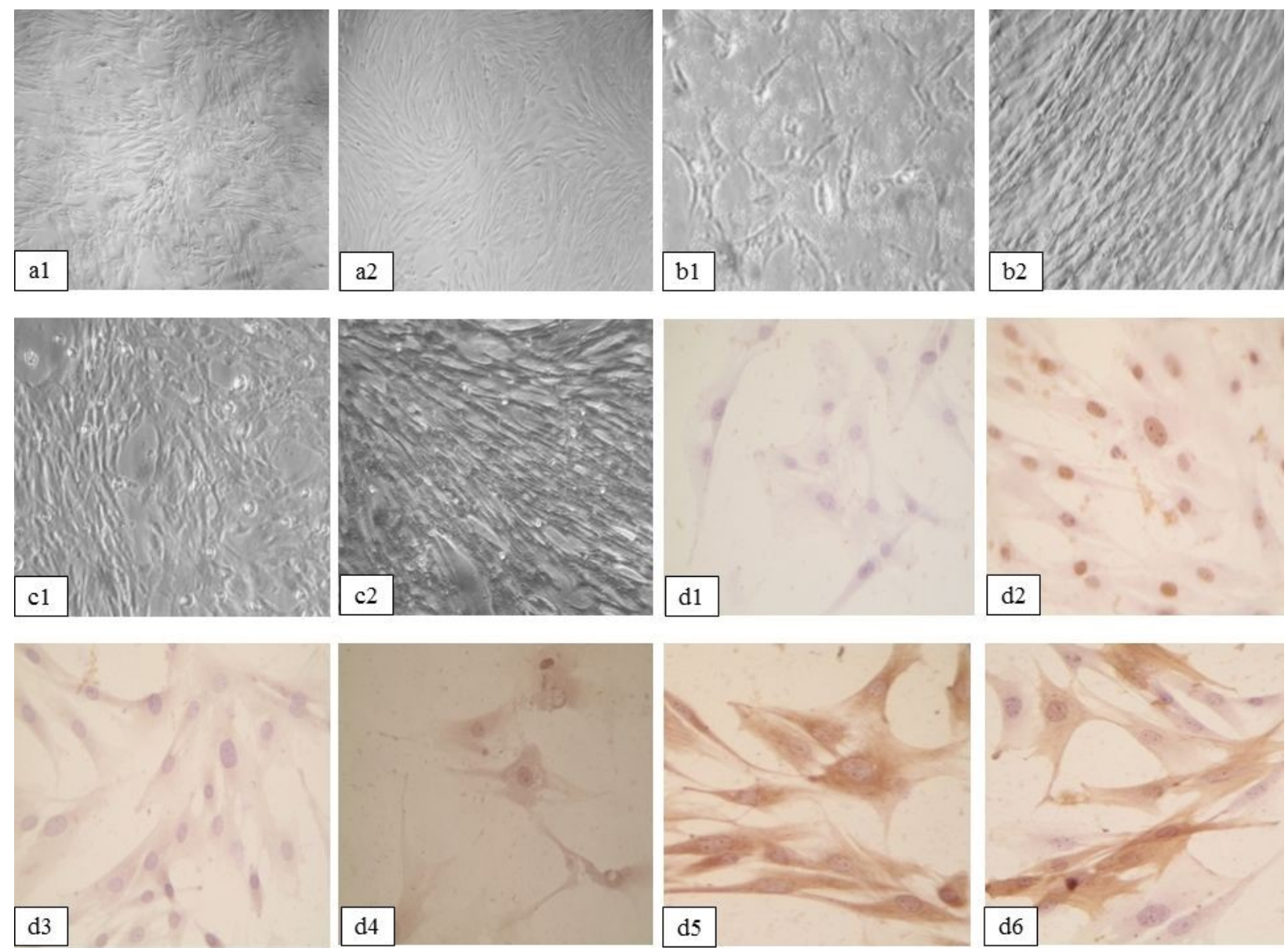

Fig. 1. A - native unstained culture of equine bone marrow mesenchymal stem cells: a1 $-2^{\text {th }}$ passage; a $2-5^{\text {th }}$ passage, $100 \times$; B - native unstained MSC culture. Formation of monolayer of primary MSC culture from foal umbilical cord (b1 - $10 \mathrm{~d}$ of cultivation, b2 - $15 \mathrm{~d}$ of cultivation), $100 \times ; \mathrm{C}-$ native unstained culture of foal umbilical cord mesenchymal stem cells: c1 $-1^{\text {st }}$ passage, c2 $-5^{\text {th }}$ passage, $100 \times$; D - immunophenotypic characterisation of equine bone marrow multipotent stem cells: d1 - control, d2 - proliferating cell nuclear antigenpositive cells; d3 - Ki-67-negative cells ( $5^{\text {th }}$ passage); d4 - Ki-67 - positive cells ( $2^{\text {nd }}$ passage), $400 \times$; d5 - vimentin-positive cells $\left(5^{\text {th }}\right.$ passage); d6 - actin-positive cells, ( $5^{\text {th }}$ passage $), 400 \times$

Table 1. Immunophenotypic profile of equine bone marrow multipotent stem cells at the early passages (mean \pm standard deviation, $\mathrm{n}=6$ )

\begin{tabular}{lcc}
\hline Antigen & Passage of cells from equine bone marrow in vitro \\
& $2^{\text {nd }}$ & $5^{\text {th }}$ \\
& Assessment in points by the H-Score method (from 0 to 300) \\
& Nuclear proteins related to proliferation and cell cycle \\
\hline PCNA & 0 & $242 \pm 22$ \\
Ki-67 & $142 \pm 11$ & 0 \\
& Proteins of cell adhesion and cytoskeleton \\
\hline Vimentin & $229 \pm 21$ & $274 \pm 11^{* *}$ \\
Actin & $128 \pm 11$ & $221 \pm 27^{*}$ \\
E-cadherin & $138 \pm 12$ & 0 \\
N-cadherin & $109 \pm 18$ & 0 \\
CD24 & $94 \pm 6$ & 0 \\
CD44 & $46 \pm 9$ & 0 \\
\hline
\end{tabular}

$* \mathrm{P}<0.01, * * \mathrm{P}<0.05$ 
During the immunophenotypic characterisation of equine bone marrow multipotent stem cells, special attention was paid to nuclear proteins associated with the proliferation and cell cycle.

The immunocytochemical analysis showed that the number of PCNA-positive cells from the equine bone marrow was significantly different at the $2^{\text {nd }}$ and $5^{\text {th }}$ passages (Table 1, Fig. 1. d1-d4). At the $2^{\text {nd }}$ passage, PCNA-positive cells were not detected, while at the $5^{\text {th }}$ passage an increase in expression to 242 points was observed. It should be noted that the expression of another protein that characterises the proliferative potential of Ki-67 was moderate (142 points) at the $2^{\text {nd }}$ passage while at the $5^{\text {th }}$ passage positive cells expressing this protein were not identified.

A specific marker of mesenchymal cells is vimentin, a protein of intermediate filaments of the cell cytoskeleton. We found a considerable number of positive cells with high activity of vimentin expression at the $2^{\text {nd }}$ passage (229 points) and a nearly $20 \%$ increase in its activity at the $5^{\text {th }}$ passage (274 points), indicating that the cells had mesenchymal origin (Table 1, Fig. 1. a1). Immunophenotyping of equine MSCs revealed a moderate number of actin-positive

cells at the $2^{\text {nd }}$ passage (128 points) and a relatively large number of actin-positive cells at the $5^{\text {th }}$ passage (221 points), which also points toward their mesenchymal origin. At the same time, we observed an interesting fact of clonal specificity - high intensity of actin expression in certain cell populations (Fig. 1. d5-d6).

When characterising equine bone marrow multipotent stem cells at the early passages, special attention was paid to cadherins - proteins responsible for $\mathrm{Ca}^{2+}$-dependent intercellular interactions, particularly during embryogenesis and tissue differentiation, including E-cadherin, which is typical of epithelial cells in adults, and N-cadherin, which is mainly found on the surface of nerve and muscle cells. The number of E-cadherin- and N-cadherin-positive cells at the $2^{\text {nd }}$ passage was 138 and 109 points, respectively, whereas at the $5^{\text {th }}$ passage these cells were not detected (Table 1, Fig. 2. a-d).

During immunophenotyping of equine MSCs after expansion in vitro, we found a small number of CD24positive cells at the $2^{\text {nd }}$ passage and the complete absence of expression of this protein at the $5^{\text {th }}$ passage (Table 1, Fig. 2. e).
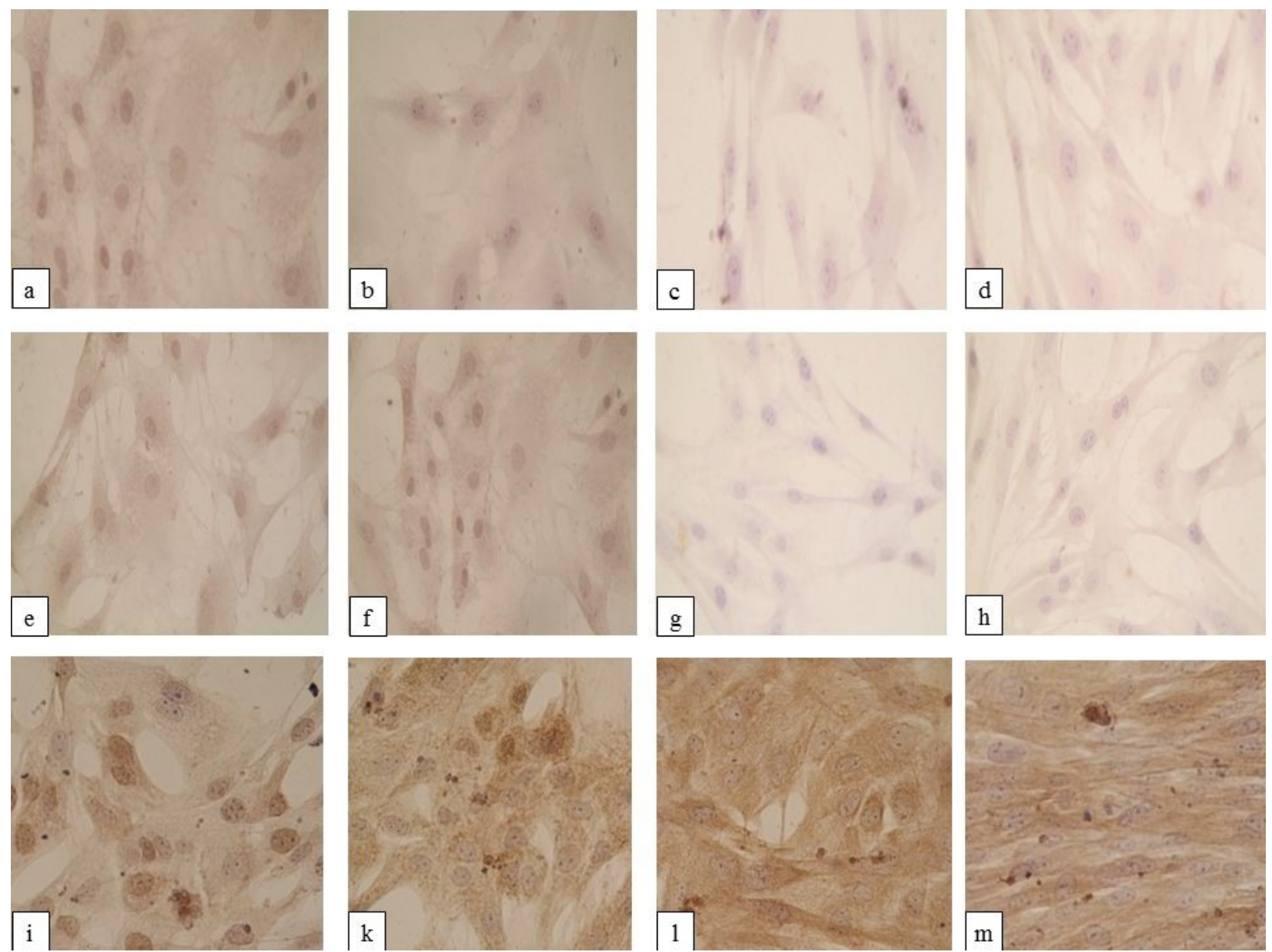

Fig. 2. Immunophenotypic characterisation of equine bone marrow multipotent stem cells: a - N-cadherin-positive cells; b - E-cadherin-positive cells $\left(2^{\text {nd }}\right.$ passage); c $-\mathrm{N}$-cadherin-negative cells; $\mathrm{d}-$ E-cadherin-negative cells ( $5^{\text {th }}$ passage); e - CD24-cadherin-positive cells; $\mathrm{f}-\mathrm{CD} 44$ cadherin-positive cells ( $2^{\text {nd }}$ passage); $\mathrm{g}-\mathrm{CD} 24$-cadherin-negative cells; $\mathrm{h}-\mathrm{CD} 44$-cadherin-negative cells $\left(5^{\text {th }}\right.$ passage), 400×. Immunophenotypic characterisation of multipotent stem cells from foal umbilical cords ( $2^{\text {nd }}$ passage): $\mathrm{i}$ - PCNA-positive cells; $\mathrm{k}$ - Ki-67-positive cells; 1 - vimentin-positive cells; $\mathrm{m}$ - actin-positive cells, 400× 
Investigation of cell adhesion protein CD44, which is the main cell membrane receptor for hyaluronate and is actively involved in the formation of physical contact between stromal cells and early precursors of B-cells, revealed a small number of CD44-positive cells at the $2^{\text {nd }}$ passage and, as in the previous case, the complete absence of CD44 expression at the $5^{\text {th }}$ passage.

Thus, the immunophenotypic heterogeneity of equine bone marrow MSCs decreased during the cultivation process. At the $5^{\text {th }}$ passage in selective medium with foetal bovine serum, the equine bone marrow multipotent stem cells displayed morphological and phenotypic homogeneity and did not contain cells expressing endothelial or haematopoietic markers.

Phenotypic characterisation of mesenchymal stem cells from foal umbilical cords. Immunocytochemical analysis of the CD-receptor system of mesenchymal stem cells from foal umbilical cords at the $2^{\text {nd }}$ passage indicates a selective dominance of mesenchymal cells over cells with epithelial and haematopoietic characteristics. The data pertaining to the immunophenotypic profile of multipotent stem cells from foal umbilical cords at the $2^{\text {nd }}$ passage are given in Table 2 and documented photographically (Fig. 2. i-m).

In the characterisation of mesenchymal stem cells from foal umbilical cords particular attention was paid to cadherins. The number of $\mathrm{E}$ - and $\mathrm{N}$-cadherinpositive cells was low, indicating very low expression of proteins that are typical for epithelial, neural, and skeletal cells of animals (Table 2). The small number of E- and N-cadherin-positive cells at the $2^{\text {nd }}$ passage demonstrates the dominance of cells with mesenchymal characteristics over cells with epithelial characteristics.

Immunophenotyping of mesenchymal stem cells from foal umbilical cords at the $2^{\text {nd }}$ passage did not detect CD24- and CD44-positive cells, which indicates the absence of haematopoietic marker expression by these cells.

Cytogenetic analysis of equine bone marrow mesenchymal stem cells. To establish the stability of mesenchymal stem cells, a comparative karyotype analysis of chromosomal variability of cells at the $3^{\text {rd }}$ and $4^{\text {th }}$ passages (Fig. 3. a-c) was conducted and compared with the level of spontaneous chromosomal variability of equine peripheral blood lymphocytes.

The results of the cytogenetic analysis of mesenchymal stem cells showed that the cells at the $3^{\text {rd }}$ and $4^{\text {th }}$ passages were characterised by quantitative karyotype disturbances, including aneuploidy, which accounted for $1.4 \%$ and $1.2 \%$ respectively (Fig. 3 ). No significant differences were found between quantitative disorders of chromosomes in the cells at different passages. No metaphase plates with polyploidy were detected in mesenchymal stem cells at the $3^{\text {rd }}$ and $4^{\text {th }}$ passages. Structural defects (chromosomal and chromatid ruptures) were not found in these cells either.

The frequency of equine mesenchymal stem cells with micronuclei at the $3^{\text {rd }}$ and $4^{\text {th }}$ passages was $1.3 \%$ and $0.8 \%$ respectively, not exceeding the level of spontaneous appearance of micronuclei in equine peripheral blood lymphocytes (Table 3 ).

The frequency of binucleated mesenchymal stem cells at the $3^{\text {rd }}$ and $4^{\text {th }}$ passages was $1 \%$ and $1.5 \%$, being within the parameters typical for mammalian spontaneous somatic mutagenesis.

Cytogenetic analysis of mesenchymal stem cells from foal umbilical cords. The results pertaining to the karyotype stability of mesenchymal stem cells from the foal umbilical cords according to the comparative analysis of chromosomal variability of cells at the $2^{\text {nd }}$, $3^{\text {rd }}, 4^{\text {th }}, 5^{\text {th }}$, and $7^{\text {th }}$ passages are shown in Fig. 3. d-g. A comparison was made with the level of spontaneous chromosomal variability of equine peripheral blood lymphocytes and mesenchymal stem cells from the bone marrow of these animals. The results of the micronucleus test of these cells are presented in Table 4 and Fig. 4. a-b.

The results of the cytogenetic analysis of mesenchymal stem cells from the foal umbilical cords showed that these cells had typical quantitative chromosome abnormalities (aneuploidy and polyploidy). The percentage of metaphase plates with aneuploidy in the cells from the $2^{\text {nd }}$ to $7^{\text {th }}$ passages was $16.7 \%$ $40.6 \%$, which is significantly higher than the spontaneous level of chromosome variability in equine peripheral blood lymphocytes $(1.98 \%-6.8 \%)$ and mesenchymal stem cells from bone marrow $(1.2 \%$ $1.4 \%)$. An increase in the percentage of aneuploidy was observed in cell populations from the $2^{\text {nd }}$ to $7^{\text {th }}$ passages, which indicates an increase in the karyotype instability of these cells with each successive passage.

The mesenchymal stem cells from the foal umbilical cords were characterised by the presence of a tetraploid karyotype $(4 \mathrm{n}=128)$, which was present in cell populations at the $2^{\text {nd }}, 3^{\text {rd }}$, and $5^{\text {th }}$ passages and constituted $25 \%, 27 \%$, and $4.8 \%$ respectively. The percentage of polyploid cells at the $2^{\text {nd }}$ and $3^{\text {rd }}$ passages exceeded the level of spontaneous chromosomal variability of equine peripheral blood lymphocytes more than five times $(0.4 \%-4.7 \%)$.

No structural disorders of chromosomes (chromosomal or chromatid ruptures) were observed in the cell populations studied.

The results of the micronucleus test indicate that the frequency of cells with micronuclei was two-five times higher than the level of peripheral blood lymphocytes with micronuclei (1.53\%o) (Table 4). An increase in the number of mesenchymal stem cells with micronuclei was accompanied by a simultaneous increase in the number of cells with aneuploidy. 
Table 2. Immunophenotypic profile of multipotent stem cells from foal umbilical cords at the $2^{\text {nd }}$ passage (mean \pm standard deviation, $\mathrm{n}=6$ )

$$
2^{\text {nd }} \text { passage }
$$

Antigen Assessment in points by the H-score method (from 0 to 300)

\begin{tabular}{lc} 
& Nuclear proteins related to proliferation and cell cycle \\
\hline PCNA & $198 \pm 13$ \\
Ki-67 & $134 \pm 23$ \\
& Proteins of cell adhesion and cytoskeleton \\
\hline Vimentin & $265 \pm 12$ \\
Actin & $244 \pm 19$ \\
E-cadherin & $11 \pm 5$ \\
N-cadherin & $64 \pm 9$ \\
CD24 & 0 \\
CD44 & 0 \\
\hline
\end{tabular}

Table 3. Results of micronucleus test of mesenchymal stem cells from equine bone marrow. Frequency in 1000 cells (\%o)

\begin{tabular}{lllll}
\hline Passage & Cells with micronuclei & Binucleated cells & Mitotic index & Apoptosis \\
\hline 3 & 1.3 & 1.0 & 3.0 & 1 \\
4 & 0.8 & 1.5 & 3.3 & 1 \\
\hline
\end{tabular}
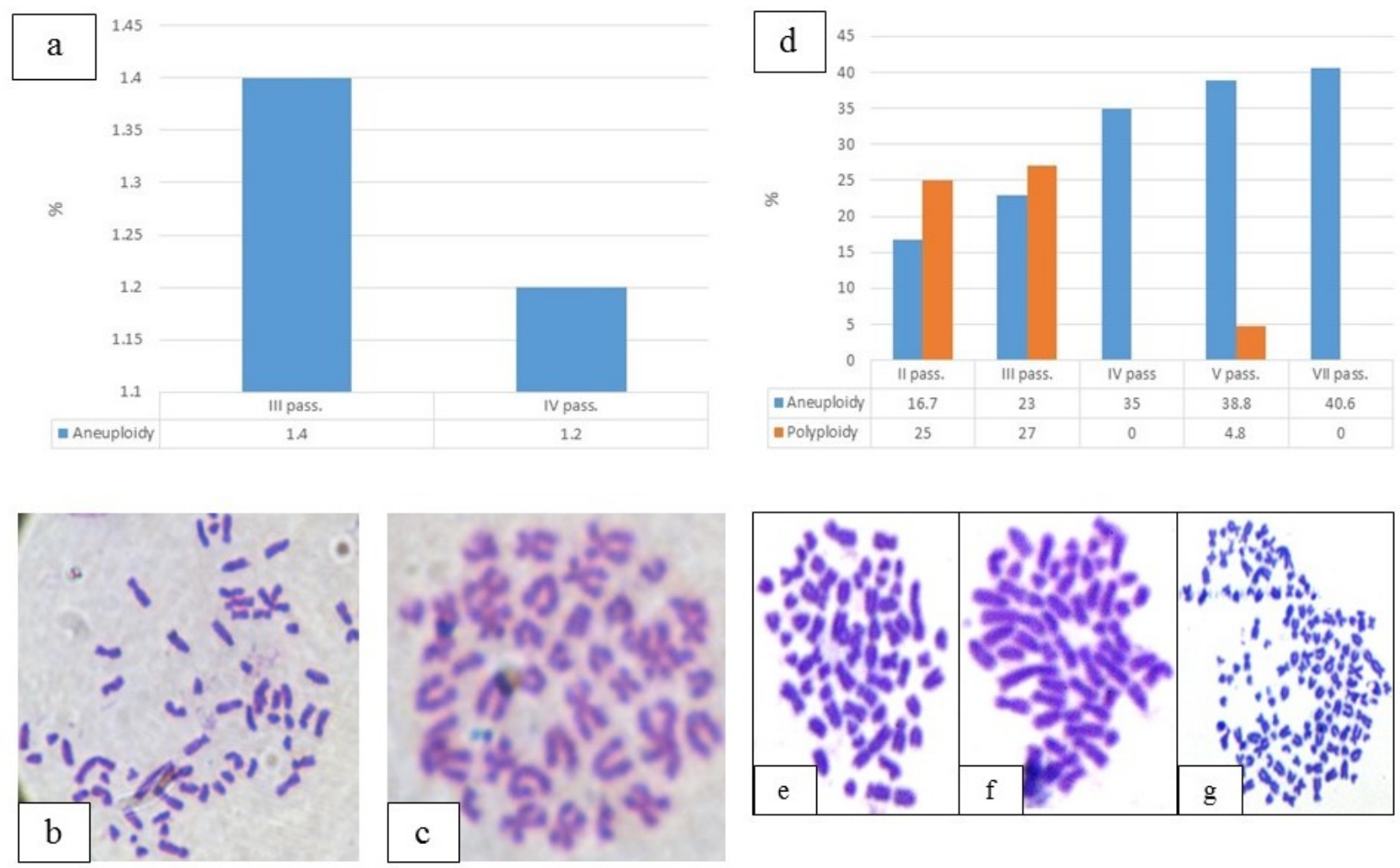

Fig. 3. Cytogenetic analysis of equine bone marrow mesenchymal stem cells: a - analysis of karyotype stability of equine bone marrow mesenchymal stem cells at the $3^{\text {rd }}$ and $4^{\text {th }}$ passages. Karyotype of mesenchymal stem cells of equine bone marrow mesenchymal stem cells $\left(5^{\text {th }}\right.$ passage $) ; \mathrm{b}-\operatorname{normal}(2 \mathrm{n}=64) ; \mathrm{c}-$ aneuploidy $(2 \mathrm{n}=59), 1,000 \times ; \mathrm{d}$ - quantitative chromosome abnormalities of mesenchymal stem cells from foal umbilical cords at the early passages. Karyotype of mesenchymal stem cells from foal umbilical cords $\left(5^{\text {th }}\right.$ passage): e - normal $(2 \mathrm{n}=64) ; \mathrm{f}-$ aneuploidy $(2 \mathrm{n}=54) ; \mathrm{g}-$ polyploidy $(4 \mathrm{n}=128), 1,000 \times$ 


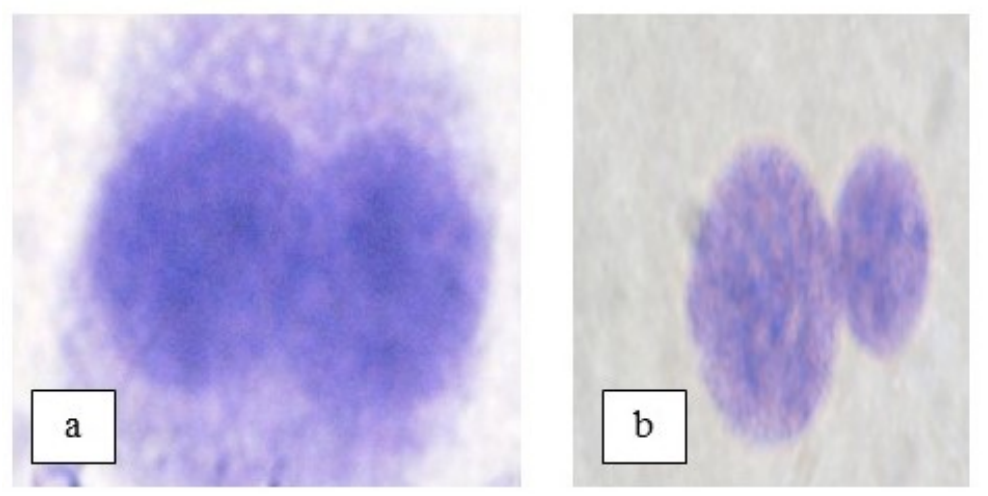

Fig. 4. Micronucleus test of mesenchymal stem cells from foal umbilical cords: $\mathrm{a}$ - binucleated cell; $\mathrm{b}$ - cell with micronuclei, 1000×

Table 4. Results of the micronucleus test performed on mesenchymal stem cells from foal umbilical cords. Frequency in 1000 cells $(\%)$

\begin{tabular}{lllll}
\hline Passage & Cells with micronuclei & Binucleated cells & Mitotic index & Apoptosis \\
\hline 2 & $1.3 \pm 0.23$ & $3.7 \pm 0.75$ & $4.0 \pm 0.5$ & - \\
3 & $4.0 \pm 0.39^{*}$ & $1.0 \pm 0.3^{* *}$ & $6.0 \pm 0.7$ & - \\
4 & $3.0 \pm 0.9$ & $2.0 \pm 0.6$ & $4.0 \pm 1.0$ & - \\
5 & $5.7 \pm 1.1^{*}$ & $2.3 \pm 0.5$ & $2.7 \pm 0.5$ & $0.7 \pm 0.2$ \\
6 & $8.0 \pm 1.2^{* * *}$ & $0.3 \pm 0.2^{*}$ & $6.0 \pm 0.9$ & $1.3 \pm 0.4$ \\
\hline
\end{tabular}

$* \mathrm{P}<0.01, * * \mathrm{P}<0.05, * * * \mathrm{P}<0.001$. Comparisons are made between passage 2 and others

\section{Discussion}

The immunocytochemical analysis showed that the number of PCNA-positive cells from the equine bone marrow was not significantly different at the $2^{\text {nd }}$ and $5^{\text {th }}$ passage. Obviously, equine bone marrow contains several clones of multipotent stem cells, which differ in the expression of specific nuclear markers that are present in the proliferating cells. Our findings are in agreement with the results obtained by other researchers (9). The mesenchymal stem cells from umbilical cords expressed specific nuclear markers which are inherent to proliferating cells. This confirms the mesenchymal nature of the cells investigated. Our results are in agreement with the studies conducted by a number of researchers $(10,12)$. The fraction of mesenchymal stem cells with aneuploidy did not exceed the level of spontaneous chromosomal variability in equine peripheral blood lymphocytes $(6,17)$. For a more complete assessment of somatic mutagenesis of mesenchymal stem cells, a micronucleus test was performed. The formation of cells with micronuclei is the result of chromosomal ruptures or defects in the mitotic spindle, which is consistent with the manifestation of aneuploidy $(15,18$, 19, 22-23). The normal frequency of cells with micronuclei in mammals is $1.6 \%{ }_{0}-5.6 \%$ o (8). Thus, the fraction of cells with micronuclei was within the normal range.

The presence of binucleated cells results from cell aging and natural extension of the duration of cytokinesis (20). The frequency of appearance of binucleated cells was in direct proportion to the mitotic index of these cells. The level of apoptotic cells at the $3^{\text {rd }}$ and $4^{\text {th }}$ passages in horses did not exceed the parameters typical for this species (6). It should be noted that the chromosome materials obtained by modified standard cytogenetic methods did not show increased levels of disruption of the cytoplasmic membrane integrity of MSCs compared to peripheral blood lymphocytes (19).

According to published data, the presence of a tetraploid karyotype leads to the cessation of division, acceleration of cellular aging, and apoptosis (1). Changes in the amount of genetic material during cultivation can lead to abnormal functioning of the cell genome and negative effects in the cell, including oncogenic transformation (5).

The mitotic activity of the investigated cells increased as well. The level of apoptotic cells at the $5^{\text {th }}$ and $7^{\text {th }}$ passages did not exceed the parameters characteristic for this animal species. The frequency of appearance of binucleated mesenchymal stem cells from the umbilical cords at the $2^{\text {nd }}, 4^{\text {th }}$, and $5^{\text {th }}$ passages exceeded the parameters characteristic of mammalian cells with spontaneous somatic mutagenesis (1.13\%o), indicating destabilisation of the cell karyotype.

In conclusion, equine bone marrow contains several clones of stem cells that differ in the expression of specific nuclear markers which are typical of proliferating cells. Mesenchymal stem cells from equine bone marrow at the $5^{\text {th }}$ passage are morphologically and phenotypically homogeneous and do not contain cells that express endothelial and 
haematopoietic markers. Stem cells from foal umbilical cords express markers which are typical of cells of mesenchymal origin and do not express haematopoietic markers. The level of karyotype variability of mesenchymal stem cells from equine bone marrow at the $3^{\text {rd }}$ and $4^{\text {th }}$ passages during in vitro cultivation corresponds to the spontaneous level typical for this species. Mesenchymal stem cells from foal umbilical cords during in vitro cultivation are characterised by quantitative abnormalities of the chromosomal apparatus. We established that the limits of micronucleus test parameters for umbilical cord mesenchymal stem cells increased in comparison with mammalian peripheral blood lymphocytes during spontaneous somatic mutagenesis.

Conflict of Interests Statement: The authors declare that they have no conflict of interests regarding the publication of this article.

Financial Disclosure Statement: We declare that the experiment was financed from the funds vested by each of the research units.

Animal Rights Statement: The experiment was approved by the Commission on Bioethics Institute of Veterinary Medicine NAAS of Ukraine, Resolution No. $1 / 2012$ for conduction of experiments on animals.

\section{References}

1. Andraszek K., Gryzinska M., Danielewicz A., Batkowska J., Smalec E.: Age-dependent stability of nucleoli and global DNA methylation level in spermatocytes of the domestic horse (Equus caballus). Can J Anim Sci 2016, 96, 215-220.

2. Barberini D.J., Freitas N.P., Magnoni M.S., Maia L., Listoni A.J., Heckler M.C., Sudano M.J., Golim M.A., da Cruz LandimAlvarenga F., Amorim RM.: Equine mesenchymal stem cells from bone marrow, adipose tissue and umbilical cord: immunophenotypic characterization and differentiation potential. Stem Cell Res Ther 2014, 5, 25, doi:10.1186/scrt414.

3. Bentivegna A., Miloso M., Riva G., Foudah D., Butta V., Dalprà L., Tredici G.: DNA Methylation changes during in vitro propagation of human mesenchymal stem cells: Implications for their genomic stability? Stem Cells Int 2013, 192425, doi:10.1155/2013/192425.

4. Bernardo M.E., Zaffaroni N., Novara F., Cometa A.M., Avanzini M.A., Moretta A., Montagna D., Maccario R., Villa R., Daidone M.G., Zuffardi O., Locatelli F.: Human bone marrow derived mesenchymal stem cells do not undergo transformation after long-term in vitro culture and do not exhibit telomere maintenance mechanisms. Cancer Res 2007, 67, 9142-9149.

5. Borgonovo T., Vaz I.V., Senegaglia A.C., Rebelatto C.L.K., Brofman P.R.S.: Genetic evaluation of mesenchymal stem cells by G-banded karyotyping in a Cell Technology Center. Rev Bras Hematol Hemoter 2014, 36, 202-207.

6. Brazil T.J., Dixon P.M., Haslett C., Murray J., McGorum B.C.: Constitutive apoptosis in equine peripheral blood neutrophils in vitro. Vet J 2004, 202, 536-542.

7. Carrade D.D., Lame M.W., Kent M.S., Clark K.C., Walker N.J., Borjesson D.L.: Comparative analysis of the immunomodulatory properties of equine adult-derived mesenchymal stem cells. Cell Med 2012, 4, 1-11.

8. Cea G.F., Etcheberry K.F., Dulout F.N.: Induction of micronuclei in mouse bone-marrow cells by the flavonoid 5,3',4'trihydroxy-3,6,7,8-tetramethoxy-flavone (THTMF). Mutat Res $198,119,339-420$

9. Colter D.C., Sekiya I., Prockop D.J.: Identification of a subpopulation rapidly self-renewing and multipotential adult stem cells in colonies of human marrow stromal cells. Proc Natl Acad Sci USA 2001, 98, 7841-7845.

10. Cremonesi F., Violini S., Lange Consiglio A., Ramelli P., Ranzenigo G., Mariani P.: Isolation, in vitro culture and characterization of foal umbilical cord stem cells at birth. Vet Res Com 2008, 32, 39-142.

11. Dyson S.J.: Medical management of superficial digital flexor tendonitis: a comparative study in 219 horses (1992-2000). Equine Vet J 2004, 36, 415-419.

12. Hoynowski S.M., Fry M.M., Gardner B.M., Leming M.T., Tucker J.R., Black L., Sand T., Mitchell K.E.: Characterization and differentiation of equine umbilical cord-derived matrix cells. Biochem Biophys Res Com 2007, 362, 347-353. Erratum in Biochem Biophys Res Com 2008, 373, 177.

13. Iacono E., Merlo B., Romagnoli N., Rossi B., Ricci F., Spadari A.: Equine bone marrow and adipose tissue mesenchymal stem cells: cytofluorimetric characterization, in vitro differentiation, and clinical application. Equine Vet J 2015, 35, 130-140.

14. Kovacs G., Soudah B., Hoene E.: Binucleate cells in a human renal cell carcinoma with 34 chromosomes. Cancer Genet Cytogenet 1988, 31, 211-216.

15. Lange-Consiglio A., Corradetti B., Rutigliano L., Cremonesi F., Bizzaro D.: In vitro studies of horse umbilical cord matrixderived cells: from characterization to labeling for magnetic resonance imaging. Open Tissue Eng Regen Med J 2011, 4, 120-133.

16. Lefort N., Feyeux M., Bas C., Féraud O., Bennaceur-Griscelli A., Tachdjian G., Peschanski M., Perrier A.L.: Human embryonic stem cells reveal recurrent genomic instability at 20q11.21. Nature Biotechnol 2008, 26, 1364-1366.

17. Maia L., Landim-Alvarenga F.C., Da Mota L.S., De Assis Golim M., Laufer-Amorim R., De Vita B., Barberini D.J., Listoni A.J., De Moraes C.N., Heckler M.C., Amorim R.M.: Immunophenotypic, immunocytochemistry, ultrastructural, and cytogenetic characterization of mesenchymal stem cells from equine bone marrow. Microsc Res Tech. 2013, 76, 618-624.

18. Migliore L., Colognato R., Naccarati A., Bergamaschi E.: Relationship between genotoxicity biomarkers in somatic and germ cells: findings from a biomonitoring study. Mutagenesis 2006, 21, 149-152.

19. Moorhead P.S., Nowell P.C., Mellman W.J., Battips D.M., Hungerford D.A.: Chromosome preparations of leukocytes cultured from human peripherical blood. Exp Cell Res 1960, 20, 613-616.

20. Pellicer J.A., Pertusa J., Alcober V.: Binuclear cells in the Ehrlich ascites tumor. Action of 5-fluorouracil. Biol Cell 1987, 60, 255-258.

21. Taghizadeh R.R., Cetrulo K.J., Cetrulo C.L.: Wharton's Jelly stem cells: future clinical applications. Placenta 2011, 32, 311-315.

22. Wójcik E., Smalec E., Danielewicz A.: Sister chromatid exchanges in selected horse breed (Equus caballus). Arch Tierzucht 2011, 54, 107-114.

23. Wójcik E., Smalec E.: The effect of environmental factors on sister chromatid exchange incidence in domestic horse chromosomes (Equus caballus). Folia Biol (Krakow) 2013, 61, 199-204.

24. Zucconi E., Vieira N.M., Bueno D.F., Secco M., Jazedje T., Ambrosio C.E., Passos-Bueno M.R., Miglino M.A., Zatz M.: Mesenchymal stem cells derived from canine umbilical cord vein - A novel source for cell therapy studies. Stem Cells Dev 2010, 19, 395-402. 